\title{
Simulation, Manufacturing and Evaluation of Injection Molded Microbioreactors
}

\author{
Felix Schütze ${ }^{1}$, Nelson Matuschek ${ }^{1}$, Steffen Zinn" ${ }^{1}$ Andrea Böhme ${ }^{1}$, Loredana Santo ${ }^{2}$, Andreas H. \\ Foitzik $^{1}$ \\ 1 University of Applied Sciences, Department of Engineering and Natural Sciences, 15745 Wildau; \\ Germany \\ 2 University of Rome Tor Vergata, Department of Industrial Engineering, Via Orazio Raimondo, 18- \\ 00173 Roma, Italy \\ fschuetze@th-wildau.de, matuschek@th-wildau.de, zinn@th-wildau.de, aboehme@th-wildau.de, \\ afoitzik@th-wildau.de, santo@uniroma2.it
}

\begin{abstract}
:
Miniaturized flow through devices offer the possibility to mimic the in vivo microenvironment for cultivated cells. In order to guaranty sterility and to eliminate the risk of cross contamination, bioreactors are commonly designed as disposable systems. In order to produce them in large numbers and at low cost, an injection molding process is necessary. Prior to the actual micro injection a simulation software is used to determine the optimal parameter for the injection molding process and machine settings. Hereby, different combinations of processing parameters can be simulated by using a test matrix. Subsequently the optimal setting is used to fabricate the bioreactor. The results are evaluated by comparing the punctual deviations of the actual surface value from the nominal surface value of the CAD-Model.
\end{abstract}

Key words: Micro bioreactor, injection molding, simulation, 3D-Scan

\section{Motivation}

With the possibility of mimicking the human organism by means of bioreactors, an attractive alternative for animal experiments is presented to investigate the efficacy and tolerability of novel drugs as well as personalized medicine. Via the cultivation of body cells and the testing of various therapeutic strategies, the most promising predictions for the therapeutic treatment could be provided. Conventional bioreactors are inappropriate for high through

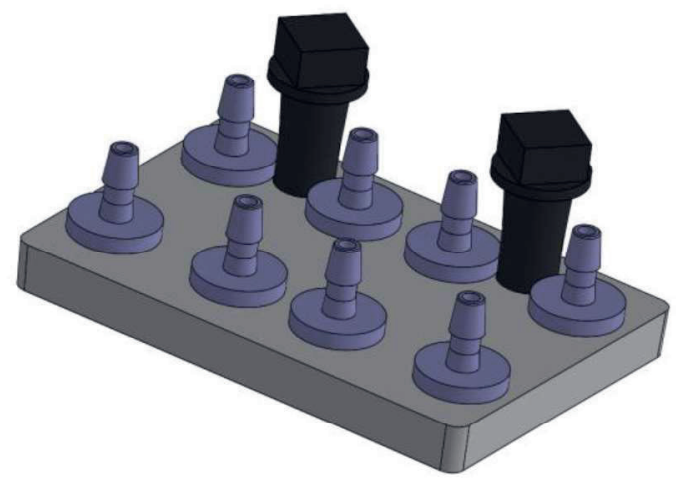

put screenings for drug testing due to their considerable amount of resources and time. Following a trend towards miniaturization, the Technical University of Applied Sciences Wildau developed a disposable miniaturized flow-through bioreactor [1]. At the moment, the bioreactor is produced via micro milling, which consumes a lot of time and effort and makes the manufacturing of the bioreactor expensive. An injection molding process is needed to produce the bioreactor in large numbers and at low costs.

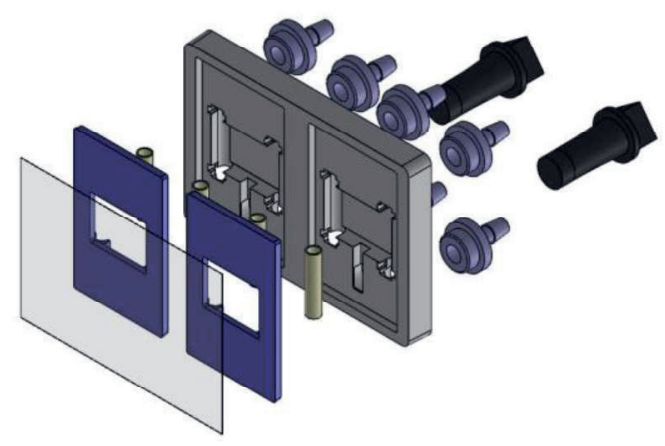

Figure 1 CAD-image of the micro bioreactor for micro injection molding, left: isometric view, bioreactor (blue) with hose connectors (orange) and seal for the inoculation port (grey); right: bottom side with hollow fibers (green) and fastening clamps. 


\section{Injection Molding}

The injection molding process is one of the most frequently used processing technologies for plastics. The process is one of the primary forming techniques, in which the solid and shapeless starting material is melted and injected into a shaping cavity [2]. An injection molding cycle consists of four consecutive steps: plastification, injection, post-pressure and demolding. The plastic granulate is melted and filled into a cylinder. The mold closes and the melted polymer is injected into the mold cavity by a translational movement. After the volumetric filling, the melt is compressed under high pressure to compensate for material shrinkage, due to the cooling. Afterwards, the tool is opened and the injection mold is demolded by ejectors [3][4].

Injection Molding offers the advantages of mass-production capability, short cycle-time, possibility of full-automatization, very accurate shape replication and dimensional control at relatively low costs [5].

\section{Polymers for Injection Molding}

The cost of raw material in most cases is relatively low, since only small material quantities are required for micro components. This makes them especially interesting for disposable products. The injection-molded thermoplastic polymers are a very large material class and can provide a suitable polymer for nearly every application. Given properties of polymers are stability against high temperatures up to $250^{\circ} \mathrm{C}$ (e.g. polyether ketone, PEEK), aggressive chemicals such as acids, alkaline solutions and solvents (e.g. polysulfone, PSU). Polymers can also be optically transparent such as PC (polycarbonate) and opaque ones such as PA (polyamide)[6].

\section{Micro Injection Molding}

Injection molding is a well-known process which has a high potential for the large-scale production of thermoplastic parts. The miniaturization of parts is a necessary step for technological progress, where more functions must be integrated into a smaller space [7]. When it comes to a definition for micro injection molding the criterions for defining a micro product are not always distinct and are continuously renewed thanks to the ongoing development of micro manufacturing technologies. The definition of a micro-molded part can be classified by factors such as weight and dimension. Parts in $3 \mathrm{~mm}$ diameter or less and parts processing a weight in the order of milligram are considered micro parts.
Macroscopic parts with several $\mathrm{cm}$ in diameter and several grams weight, which are displaying structures or tolerances in micrometer-range are considered micro-featured parts. According to the displayed definitions, the current work deals with micro-featured parts [8].

\section{Processing parameters}

The chosen processing parameters have great influence on the quality of the product. The most important parameters are melting temperature, tool temperature and injection speed. Furthermore the quality is influenced by holding pressure, holding pressure time, cooling time and the tool geometry. By means of a low mold temperature cycle time can be reduced, thus material degradation is low. On the other hand, a high mold temperature reduces mechanical stress and assures optimum properties. The tool temperature has a similar influence on the material as the mold temperature.

\section{D-Scanning}

To analyse the accuracy of the injection molding a 3-dimensional scan of the molded parts was made. Therefore an Atos Triple Scan by Gom, Germany was used. Utilizing a high definition camera the device creates a 3dimensional image of the displayed part. Software assembles 36 single images of the mold part into one 3-dimensional image. The image is used to generate a surface mesh, which is later converted into a polygon. By laying the polygon over the original CAD-image the deviations between the both can be highlighted.

\section{Leakage Tightness Test}

For a later use of the microreactors as a perfusion culture system it is crucial that cells are retained in the cultivation chamber. In order to ensure the tightness of the fabricated microreactors a microscopic leakage test with fluorescent cyanobacteria (chlorophyll A, excitation 435/40 nm; emission $515 \mathrm{~nm}$ LP) was established: Hollow fibers and connections were filled with BG-11 media and $200 \mu$ l viable cyanobacteria (Synechocystis sp. PCC 6803; approx. $5 \times 10^{\wedge} 7$ cells $/ \mathrm{ml}$ ) were inoculated in the reaction chamber. A computer controlled micropump (Diluter 4x, Gesim, Großerkmannsdorf, Germany) was connected with a flexible tube to one connector. In the first experimental set-up all remaining connectors were sealed to test the overall tightness of the reactor. Media was pumped into the reactor until the gas-permeable membrane was tightly stretched. Resulting leakages were detected by naked eye or by microscopy. In a second 
experimental set-up the connection of the micropump was varied and all connectors were sealed apart from the diagonally positioned. Thus a crossflow was achieved as intended in the later use. Flow rates were varied within a range of $2 \mu \mathrm{l} / \mathrm{min}$ up to $2 \mathrm{ml} / \mathrm{min}$. Flow-through fluids were collected and examined for any contaminating cyanobacteria[9].

\section{Experimental Approach}

In order to enable an optimal production process of the bioreactor, the filling operation was simulated with special software. For this purpose the network, forming the surfaces of the bioreactor CAD-model, has been adapted to allow an accurate prediction in a relatively short amount of time. Using Design of Experiment different parameters, like melting temperature, mold temperature, tool temperature and cooling time, were tested and the results evaluated. After the determination of the sufficient machine settings and processing parameters, the bioreactor was produced via injection molding. The molded plastic is polycarbonate since it is well suited for biomedical applications. In order to verify the simulation, the bioreactor was processed using different parameter combinations. The manufactured parts were finally examined for their quality. The degree of filling was determined by quantifying the weight of the components. Furthermore, the components were analyzed microscopically for binding seams, air inclusions and incisions. The deformation and distortion were determined by means of a 3D scan.

\section{Simulation of processing parameters}

The processing parameters can have a great influence on the quality of the parts. In this work, the influence of the injection time, the mold temperature, the melting temperature and the cooling time are investigated. In all experiments, the micro bioreactor was meshed in the same manner. Subsequently, filling simulations with different process parameters were carried out. Table 1 show the variation of the different process parameters, while table 2 illustrates the Design of Experiment matrix to determine the most promising processing parameters combination.

Table 1 processing parameters used for the simulation of the molding process

\begin{tabular}{lll}
\hline process parameters & Hight value & Low value \\
\hline melt temperature ${ }^{\circ} \mathrm{C}$ & 300 & 260 \\
mold temperature ${ }^{\circ} \mathrm{C}$ & 80 & 30 \\
injection time sec & 3 & 0.6 \\
cooling time sec & 10 & 1 \\
\hline
\end{tabular}

Depending on the combination of the parameter the maximum injection pressure has chanced (fig. 2). The parameter set number 1 to 8 the melt temperature has a value of $300{ }^{\circ} \mathrm{C}$. At the set number 9 to 16 the melt temperature is decreased to a value of $260{ }^{\circ} \mathrm{C}$. The exact combination of the parameter sets is shown table 2 .

Table 2 experimental matrix used for the CFD simulation, high value $=1$, low value $=2$

\begin{tabular}{ccccc}
\hline $\begin{array}{c}\text { set } \\
\text { number }\end{array}$ & $\begin{array}{c}\text { melt } \\
\text { temp. } \\
{ }^{\circ} \mathrm{C}\end{array}$ & $\begin{array}{c}\text { mold } \\
\text { temp } \\
{ }^{\circ} \mathrm{C}\end{array}$ & $\begin{array}{c}\text { Inject. } \\
\text { time } \\
\text { sec }\end{array}$ & $\begin{array}{c}\text { Cool. } \\
\text { time } \\
\text { sec }\end{array}$ \\
\hline 1 & 300 & 80 & 3 & 10 \\
2 & 300 & 80 & 3 & 1 \\
3 & 300 & 80 & 0,6 & 10 \\
4 & 300 & 80 & 0,6 & 1 \\
5 & 300 & 30 & 3 & 10 \\
6 & 300 & 30 & 3 & 1 \\
7 & 300 & 30 & 0,6 & 10 \\
8 & 300 & 30 & 0,6 & 1 \\
9 & 260 & 80 & 3 & 10 \\
10 & 260 & 80 & 3 & 1 \\
11 & 260 & 80 & 0,6 & 10 \\
12 & 260 & 80 & 0,6 & 1 \\
13 & 260 & 30 & 3 & 10 \\
14 & 260 & 30 & 3 & 1 \\
15 & 260 & 30 & 0,6 & 10 \\
16 & 260 & 30 & 0,6 & 1 \\
\hline
\end{tabular}

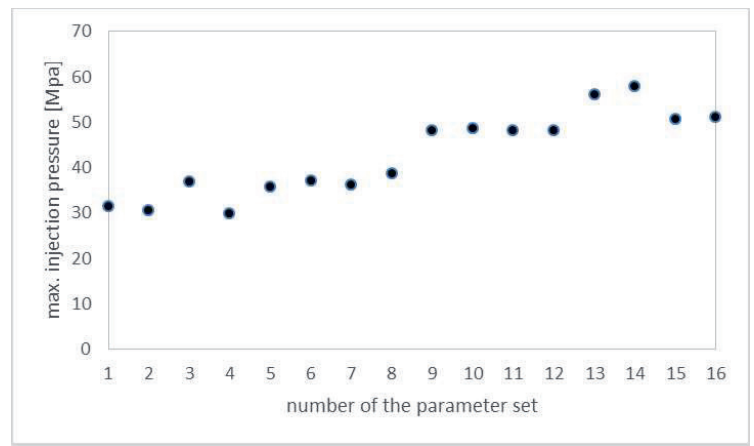

Figure 2 Changing of the melt temperature according to the sets shown in table 2

The maximum injection pressure shows the combination of the parameter set number 14. A melt temperature and a mold temperature with the low value leads to the higher injection pressure, because more pressure is needed to fill the cavity. Basically, a low pressure is preferred because of less mechanical stress. Therefore, and due to the analysis of other simulation results the parameter combination of set number 1 to 4 is preferable.

\section{Micro injection molding of the reaction chamber}

A two-sided tool for the micro injection molding was manufactured via micro milling. The tool 
was produced from CAD-designs using CAD/CAM processing chains. After the determination of the sufficient machine settings and processing parameters, the bioreactor was produced via injection molding. As material polycarbonate (Makrolon, Bayer Material Science AG) was used since it is well suited for biomedical applications. Prior to the injection molding, the polycarbonate was dried at $110^{\circ} \mathrm{C}$ for 2 hours by utilizing an additional drying unit.

In order to compare the results from the CFD simulation with the real injection molding process, different combinations of processing parameters were tested for the micron injection molding process. The filling time was altered between $0,1 \mathrm{~s}$ and $3 \mathrm{~s}$, the mold temperature between 260 and $300^{\circ} \mathrm{C}$, the tool temperature between 30 to $80^{\circ} \mathrm{C}$. The cooling time was varied from 1 to 10 seconds. The following pictures shows the comparison between simulation and real data, by varying the degree of filling.
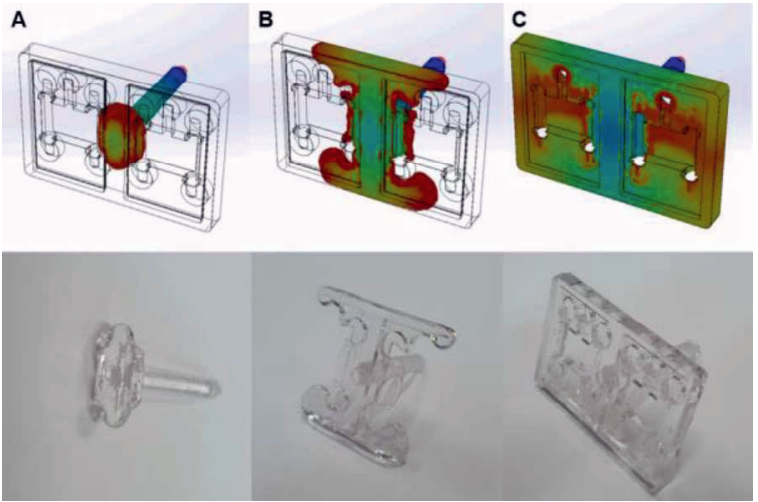

Figure 3 Filling process during simulation (top), and in reality, fron left to right: different degree of filling (0.1s, 0.3s, 0.6s)

A simulation is not a guarantee that certain results also occur in reality, since a simulation is not a representation of reality, but rather a calculated probability. This is especially important in the micro domain, since other laws are valid here than in the macro domain. Comparing the formation of the weld lines between simulation and reality reveals the difference. Figure 4 b) shows the weld line as it was also shown in the simulation. Figures 3 a) and $3 \mathrm{c}$ ) are not completely filled, no weld lines are visible.

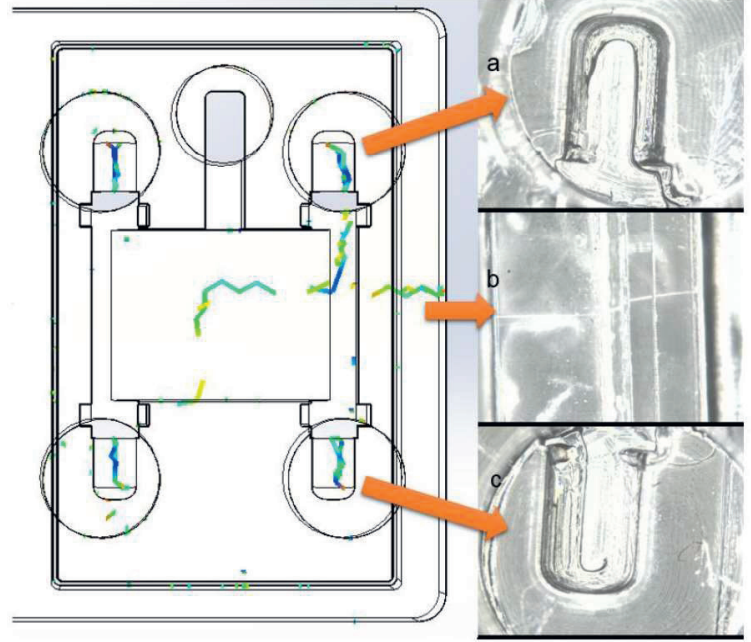

Figure 4 left: weld lines computated by the simulation, right: microscopical recordings of the weld lines from the molding process

Figure 4 shows the weld line as it was also shown in the simulation. In figures a) and c), the molds are not completely filled. Instead of a weld line there is a defect, since the injected structure is in micro-range. Clearly, the chosen process conditions are not sufficient to completely image this microstructured surface.

\section{D-scanning of the micro bioreactor}

For further evaluation of the injection molding quality, a 3D-scan was performed on the manufactured micro bioreactor. The obtained data of the high-resolution cameras are combined into a surface network, from which a graphical object (Polygon) is created. For better comparability, the CAD image of the micro bioreactor is laid over the 3D scan. Figure 5 displays the results of the studies. It can be seen that the polygon and CAD-image fit one above the other, thus no shrinkage of the outer dimensions of the component occurred.
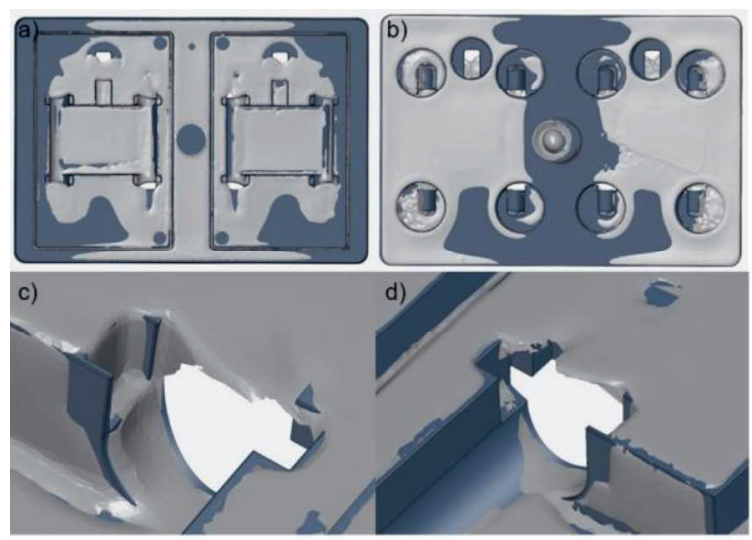

Figure 5 Superposition of the polygon (lightgrey) and the CAD-image of the micro bioreactor, a) front, b) back, c) and d) Fixations for the hollow fibers

Figure $5 \mathrm{c}$ ) and d) shows the fixations for hollow fibers. It can be seen that the inner fixation are 
not shown on the injection molded part. Furthermore, it is noticeable that most of the edges are rounded or deformed. A fully functional component could be produced, despite no optimal micro injection molding quality was achieved.

\section{Manufacturing of the micro bioreactor}

The micro bioreactor displayed in this work consists, in addition to the reaction chamber, of further individual parts. This includes the fastening clamps, which fix the hollow fibers in position and seal the reactor chamber. Using the information gained from the manufacturing of the reaction chamber, the fastening clamps are produced via micro injection molding (Fig. 6). Compared to the reaction chamber, this component is rather prone to failure, due to the simpler design of the part. The best quality was achieved with a high melting temperature $\left(300^{\circ}\right.$ $\mathrm{C})$, a high injection time (1 s) and a high cooling time (10 s). The high cooling time is necessary, so that the fastening clamps do not bend during ejection.

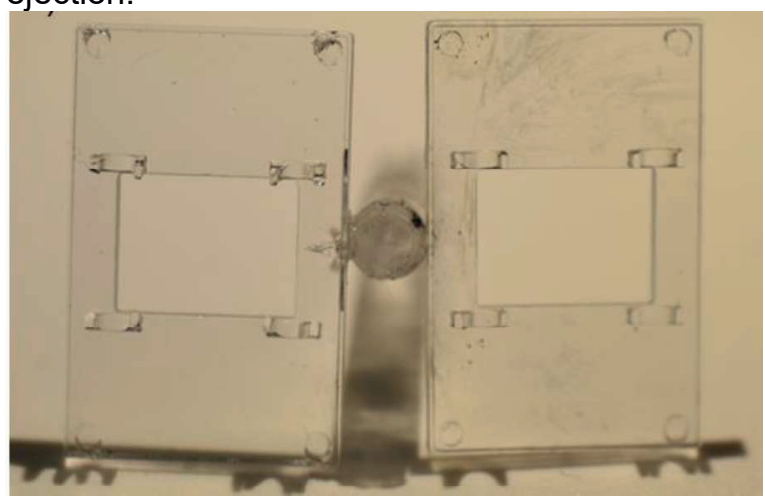

Figure 6 manufactured fastening clamps with sprue

After the manufacturing of the reaction chamber and the fastening clamps, the micro bioreactor can be assembled. The molded parts are separated from the sprue-pin. Next, the hollow fibers were set in place and fixed with biocompatible adhesive. The hollow fibers are a central component, since they limit the reactor and at the same time allow exchange of nutrient, while retaining the cultivated cells. The fastening clamps are joined with the reaction chamber using adhesive. Hose attachments were set into the provided holes on the reaction chamber. In a last step, the reaction chamber is sealed with a gas permeable membrane.

\section{Leakage tightness tests}

The tightness of the manufactured reactor was examined using cyanobacteria and a fluorescence microscope (Ex 435/40 nm; Em $515 \mathrm{~nm}$ LP). The bioreactor is filled via the inoculation port (see figure 1) with cyano bacteria, as displayed in figure $7 \mathrm{~b}$ ). The cyano bacteria performed excellent due to their strong auto fluorescence and their uniform size distribution. In the examination the red fluorescent of the cyanobacteria's chlorophyll A was used. For better identification, the fluorescence is shown as green. Figure 6b) shows the same micro bioreactor after a crossflow was achieved. It can be seen, that most of the bacteria accumulated on the left side at the hollow fibre, following the direction of the crossflow. They are hold in place, unable to leave the reaction chamber. The bioreactor can be considered impermeable for cells less the size of the cyanobacteria.
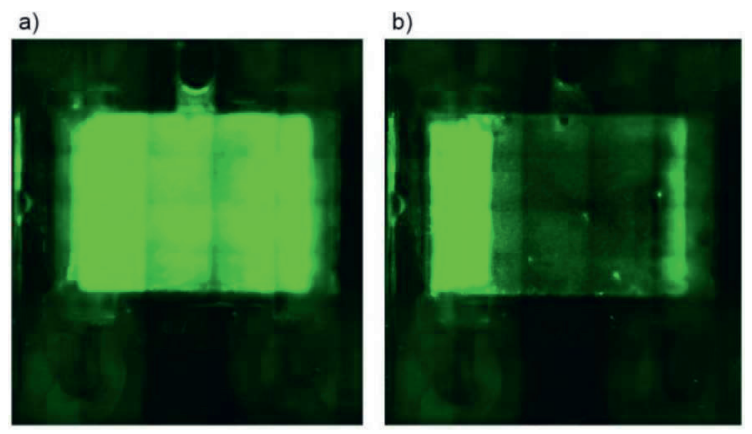

Figure 7 leakage thightness test with cyanobacteria, a): before flushing,b): after flushing with buffer

\section{Summary}

This works presents the production of a micro bioreactor via injection molding, offering the possibility to manufacture in high numbers and at lower cost. The long-term goal is to provide a modular cultivation system for immunologic testing that transfers the organoid testing environment of human artificial lymph nodes [10] into a miniaturized reactor system.

\section{References}

[1] A. Böhme, Development and Manufacture of a miniatured flow through-put (multiple) Bioreactor System, 2016, University of Rome Tor Vergata

[2] E. Werner, E. Hornbogen, N. Jost, G. Eggeler, Werkstoff Und Fertigung, Fragen Und Antworten Zu Werkstoffe, 2012

[3] W. Michaeli, C. Hopmann, Einführung in die Kunststoffverarbeitung, 7. Überarbeitete und erweiterte Auflage, 2015, Carl Hanser Verlag, Munich

[4] L. Jiqing, Erhöhung der Reproduzierbarkeit des Sprutzgießprozesses durch verbesserte Plastifizierkonzepte, 2010, Technische Universität München

[5] C. Yang, X. Yin, G. Cheng, Microinjection molding of microsystem components: new aspects in improving performance, Journal of Micromechanics and Microengineering, 2013, doi:10.1088/0960-1317/23/9/093001 
[6] M. Heckele, W. Schomburg, Review on micro molding of thermoplastic polymers, Journal of Micromechanics and Microengineering, 2003, DOI: $10.1088 / 0960-1317 / 14 / 3 /$ R01

[7] J. Giboz, T. Copponnex, P. Mele, Microinjection molding of thermoplastic polymers: Morphological comparison with conventional injection molding, Journal of Micromechanics and Microengineering, 2009, DOI: 10.1088/0960$1317 / 19 / 2 / 025023$

[8] F. Chiou, B. Bhushan, Microinjection Molding, Encyclopedia of Nanotechnology, Springer Netherlands, 2014

[9] A.Böhme, L.Radke, F. Schütze, S. Schneider, T. Liebscher, L. Santo, F. Fabrizio, M. Hummel, C. Giese, M. Frohme, A. Foitzik, Minituarized flowthrough bioreactor for processing and testing in pharmacology, Thermec'2016 International Conference on Processing and Manufacturing of Advanced Materials, Graz 2016

[10] C. Giese, A. Lubitz, C.D. Demmler, J. Reuschel, K. Bergner, U. Marx, Immunological substance testing on human lymphatic micro-organoids in vitro, J. Biotechnol. 148 (2010) 38-45. 